\title{
openheart GRACE score and cardiovascular outcomes prediction among the delayed coronary intervention after post- fibrinolytic STEMI patients in a limited PCI-capable hospital
}

Yotsawee Chotechuang (D , , ${ }^{1,2}$ Arintaya Phrommintikul, ${ }^{3}$ Srun Kuanprasert, ${ }^{3}$ Roungtiva Muenpa, ${ }^{4}$ Chidchanok Ruengorn, ${ }^{5,6}$ Jayanton Patumanond, ${ }^{7,8}$ Tuanchai Chaichuen, ${ }^{9}$ Noparat Thanachaikun, ${ }^{3}$ Thanawat Benjanuwatra, ${ }^{3}$ Apichard Sukonthasarn ${ }^{3}$

To cite: Chotechuang Y, Phrommintikul A, Kuanprasert S, et al. GRACE score and cardiovascular outcomes prediction among the delayed coronary intervention after postfibrinolytic STEMI patients in a limited PCl-capable hospital. Open Heart 2020;7:e001133. doi:10.1136/ openhrt-2019-001133

Received 10 July 2019 Revised 21 November 2019 Accepted 20 February 2020
Check for updates

(C) Author(s) (or their employer(s)) 2020. Re-use permitted under CC BY-NC. No commercial re-use. See rights and permissions. Published by BMJ.

For numbered affiliations see end of article.

Correspondence to Dr Arintaya Phrommintikul; arintayap@yahoo.com

\section{ABSTRACT}

Background In Thailand, due to limited availability of percutaneous coronary intervention (PCI)-capable hospitals, a number of patients with ST-elevation myocardial infarction (STEMI) after fibrinolytic therapy underwent the delayed coronary intervention (24 hours to 2 weeks). Existing tool such as the Global Registry of Acute Coronary Event (GRACE) to define patients at high risk of cardiovascular outcomes has been used widely, except for patients who had the delayed coronary intervention. We, therefore, evaluated the cardiovascular outcomes of STEMI patients who underwent the delayed coronary intervention. Methods We retrospectively analysed the data from the PCl-capable hospital (Maharaj Nakorn Chiang Mai Hospital) STEMI registry during the period 2007-2012. Patients who received fibrinolytic treatment (SK) and underwent the delayed coronary intervention were included. The outcomes of the study were 30-day and 6-month composite cardiovascular outcomes (including death, rehospitalised with acute coronary syndrome, re-hospitalised with heart failure and stroke).

Results Of all 341 patients included, 229 (67.2\%) patients were in the low GRACE score group ( $<126$ points) and $112(32.8 \%)$ patients in the intermediate-high GRACE score group ( $\geq 126$ points). At 30 days, the composite cardiovascular outcome occurred in $2.2 \%(n=5)$ in the low GRACE score group and $11.6 \%(n=13)$ in the intermediatehigh GRACE score group ( $p$ value=0.001). At 6 months, the composite cardiovascular outcomes occurred in 3.9\% $(n=9)$ in the low GRACE score group and $13.4 \%(n=15)$ in the intermediate-high GRACE score group ( $p$ value $=0.003$ ). The area under the receiver operating characteristic curve of GRACE score for 6-month composite cardiovascular outcomes was 0.746 ( $95 \% \mathrm{Cl} 0.698$ to 0.793$)$.

Conclusion Intermediate-high GRACE risk STEMI patients after fibrinolytic therapy in limited PCl-capable hospital who underwent the delayed coronary intervention increased 30-day and 6-month cardiovascular outcomes compared with the low GRACE risk patients. In limited available PCl-capable hospital, GRACE risk score can be helpful in guiding the cardiologists to select a proper

\section{Key messages}

What is already known about this subject?

- The delayed coronary intervention in intermediatehigh Global Registry of Acute Coronary Event (GRACE) risk ST-elevation myocardial infarction (STEMI) patients after successful fibrinolytic therapy in non-percutaneous coronary intervention (PCI)capable hospital has been shown to be worsening cardiovascular outcome compared with low GRACE risk score patients. However, the cardiovascular outcomes of the patients who underwent the delayed coronary intervention in limited PCl-capable hospital are still uncertain.

What does this study add?

- The delayed coronary intervention (24 hours to 2 weeks) in intermediate-high GRACE risk STEM patients in PCl-capable hospital has increased the rate of cardiovascular outcomes compared with low GRACE risk STEMI patients as same as in non-PClcapable hospital.

How might this impact on clinical practice?

- Intermediate-high GRACE risk STEMI patients after successful fibrinolytic therapy in limited available $\mathrm{PCl}$-capable hospital should undergo an early coronary intervention. GRACE risk score may be helpful and guided cardiologists to select the proper time for coronary intervention in post-fibrinolytic STEMI patients in limited available PCl-capable hospital situation.

time for coronary intervention in post-fibrinolytic STEMI patients.

\section{INTRODUCTION}

Primary percutaneous coronary intervention (PPCI) is also known as the gold standard in 


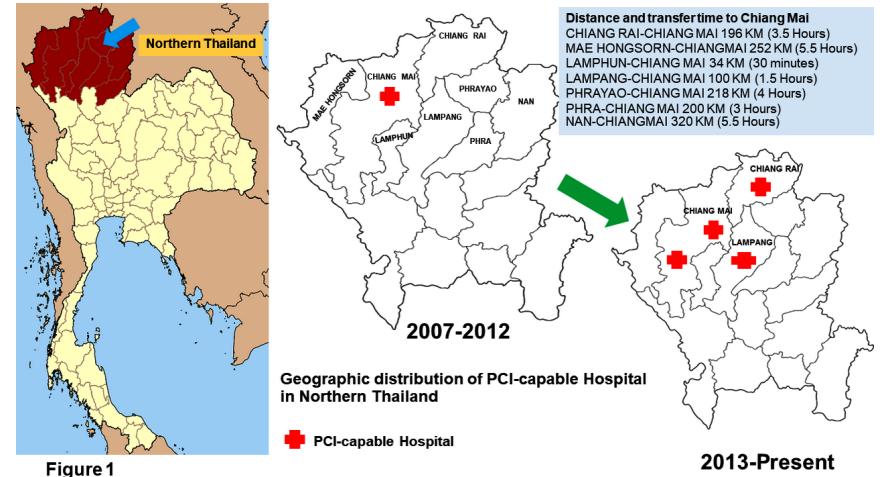

Figure 1 Geographic distribution of $\mathrm{PCl}$-capable hospital in the Northern Thailand according to the period of time.

reperfusion treatment of ST-elevation myocardial infarction (STEMI) patients. The limitation of the numbers and availability PCI-capable hospitals in the Northern Thailand, fibrinolytic therapy, streptokinase (SK), is still the first modality for reperfusion treatment in this situation. Several guidelines recommend to perform an early routine coronary angiogram (CAG) or early coronary intervention (3-24 hours) in this group of the patients. ${ }^{1-5}$ However, the availability of PCI-capable hospitals (24/7) and limited resources (human resources) in some developing countries, including Thailand, the early routine coronary intervention after fibrinolytic treatment was not always feasible.

In the Northern Thailand, only one PCI-capable centre (Maharaj Nakorn Chiang Mai Hospital) was available to support eight upper provinces during the period 20072012 (figure 1). Referral mean among this geographic mountainous area is time consumed to Maharaj Nakorn Chiang Mai hospital (figure 1). Moreover, having only few interventional cardiologists and 24/7 PCI-capable hospitals, primary PCI and early coronary intervention after fibrinolytic treatment were very difficult to perform. Rescue PCI or primary PCI is a treatment for patients who have unsuccessful fibrinolytic therapy or presented with cardiogenic shock. The combination strategy of lytic therapy followed by coronary intervention is appropriate for STEMI patients in this area. As a result, most of the STEMI patients in the Northern Thailand received fibrinolytic therapy and underwent delayed coronary intervention (more than 24hours after fibrinolytic therapy) and some of them received elective PCI or long delayed intervention or elective PCI (more than 2 weeks).

The data of Thailand Registry in Acute Coronary Syndrome (TRACS) demonstrated a low rate of cardiac intervention during index admission and referral centres for an early coronary intervention were also limited. ${ }^{6}$ Existing tool such as the Global Registry of Acute Coronary Event (GRACE) to define patients at high risk of cardiovascular outcomes has been used widely, except for patients who had the delayed coronary intervention. Previous study demonstrated the worsening cardiovascular outcomes in the intermediate-high GRACE risk patients who underwent the delayed coronary intervention in non-PCI-capable centre. ${ }^{7}$ However, some of the STEMI patients in PCI-capable centre also underwent a delayed coronary intervention after fibrinolytic therapy but no data demonstrate the cardiovascular outcomes in this group of patients.

The objectives of the study were to evaluate the cardiovascular outcomes in the STEMI patients who underwent a delayed coronary intervention after fibrinolytic treatment and the usefulness of GRACE score to predict the cardiovascular outcomes in limited PCI-capable hospital situation.

\section{METHODS}

\section{Study design and population}

It was a retrospective cohort study. The data from Maharaj Nakorn Chiang Mai Hospital (PCI-capable hospital) STEMI registry during the period 2007-2012 were analysed. The post-fibrinolytic therapy STEMI patients who underwent a delayed coronary intervention (24hours to 2 weeks) were included in our study.

The exclusion criteria included the patients who failed fibrinolytic therapy (decreased in elevation of ST-segment $<50 \%$ at $90 \mathrm{~min}$ ), performed an early coronary intervention $(<24$ hours), underwent very long delayed coronary intervention ( $>2$ weeks), the patients who refused for further interventions after fibrinolytic therapy, underwent PPCI or rescue PCI and previous history of coronaryartery bypass surgery. The study flow diagram is shown in figure 2 .

The data were collected including the baseline demographics data, medical history, presentation symptoms, baseline GRACE score, time to coronary intervention, angiographic data, procedural performed and clinical cardiovascular outcomes. In patients who did not visit the hospital, the telephone calls by a research team were made to evaluate the clinical outcomes.

\section{Definitions}

The STEMI was defined as the presence of at least $0.1 \mathrm{mV}$ ST-segment elevation or new or presumably new left bundle branch block with elevation of cardiac enzymes. Successful fibrinolytic treatment was defined as the ST-segment decrease in elevation more than $50 \%$ at $90 \mathrm{~min}$ after fibrinolytic treatment. Delayed coronary intervention means CAG or PCI performed during 24 hours to 2 weeks after successful fibrinolytic therapy. The GRACE score was composed of medical history, findings at initial presentation and findings during hospitalisation (0-258 points). The patients were stratified into low GRACE risk score group (GRACE $<126)$ and intermediate-high risk score group (GRACE $\geq 126) .{ }^{7}$ Culprit vessel PCI means PCI to culprit vessel lesion only. The multi-vessel PCI means PCI $\geq 1$ non-culprit vessel lesions.

\section{Outcomes measurement}

The outcomes of the study were 30-day and 6-month composite cardiovascular outcome including death, re-hospitalisation with acute coronary syndrome (ACS), 


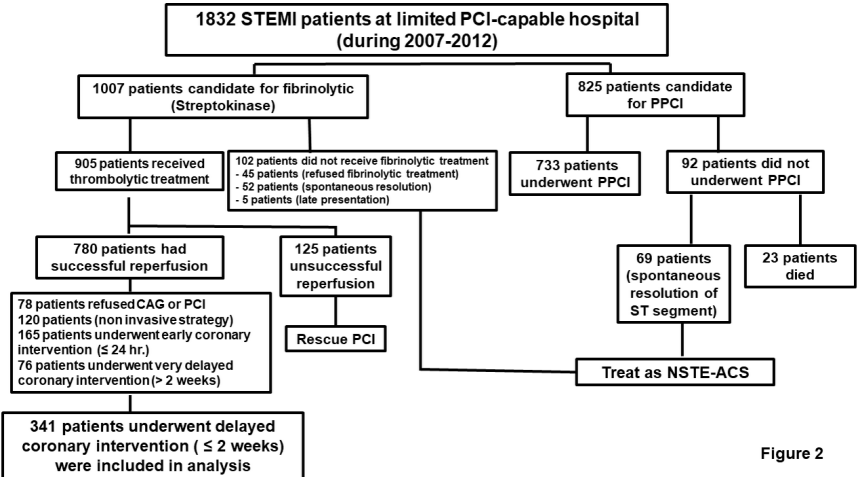

Figure 2 Study flow diagram. CAG, coronary angiogram; $\mathrm{PCl}$, percutaneous coronary intervention; $\mathrm{PPCl}$, primary percutaneous coronary intervention; STEMI, ST-elevation myocardial infarction; NSTE-ACS, non ST-segment elevation acute coronary syndromes or acute coronary syndromes without ST-segment elevation.

re-hospitalisation with heart failure $(\mathrm{HF})$ and stroke at 30-day and 6-month composite cardiovascular outcome.

\section{Statistical analysis}

Baseline characteristics and angiographic data were presented as mean $\pm \mathrm{SD}$ or median and IQR. The categorical data were presented as numbers and percentages. Differences in continuous variables were analysed with the Student's t test or Wilcoxon's rank-sum test. The categorical variables were analysed with $\chi^{2}$ test or Fisher's exact test. $\mathrm{P}$ value $<0.05$ was set for statistically significance. Composite clinical cardiovascular outcomes were presented as numbers and percentages. The composite outcome was analysed using time-to-event analysis and illustrated with Kaplan-Meier curve, HR and 95\% CI.

The usefulness of GRACE score on predictive clinical outcomes was predicted using logistic regression analysis and the area under the receiver operating characteristics curve (AuROC) was also calculated. All statistical analyses were conducted using Stata V.13.1 (Stata Corporation).

The sample size was estimated based on our earlier study $^{7}$ with the OR 3.2 of the 6-month composite cardiovascular outcome between intermediate-high GRACE group versus the low GRACE group in non-PCI-capable centre. To achieve a power of $90 \%$, with a type- 1 error probability of $5 \%$ (two-sided), allowable estimated error (margin error) of 5\%, 340 patients were needed in this study.

\section{RESULTS}

\section{Baseline demographics}

Of 1832 STEMI patients, 1007 patients were candidates for fibrinolytic therapy. Nine hundred and five patients received fibrinolytic therapy and 780 patients had successful reperfusion therapy with SK, and 341 patients underwent the delayed coronary intervention, as shown in figure 2. Two hundred and twenty-nine patients were in low GRACE risk score group and 112 patients were intermediate-high GRACE risk score group. All of the
Table 1 Baseline demographics according to GRACE risk score $(n=341)$

\begin{tabular}{|c|c|c|c|}
\hline Clinical characteristics & $\begin{array}{l}\text { Low GRACE } \\
\text { score group } \\
\text { ( } n=229)\end{array}$ & $\begin{array}{l}\text { Intermediate- } \\
\text { high GRACE } \\
\text { score group } \\
(n=112)\end{array}$ & $P$ value \\
\hline Age (years), mean $\pm S D$ & $57.4 \pm 9.1$ & $68.3 \pm 8.7$ & $<0.001$ \\
\hline \multicolumn{4}{|l|}{ Gender, (\%) } \\
\hline Male & $135(59.0)$ & $65(58.0)$ & 0.907 \\
\hline $\begin{array}{l}\text { Time from symptoms onset } \\
\text { to fibrinolytic therapy, median } \\
\text { (hours) (IQR: 25th, 75th } \\
\text { percentile) }\end{array}$ & 2.8 (IQR: 2,4.0) & 2.9 (IQR: 2,4.6) & 0.571 \\
\hline $\begin{array}{l}\text { Time from fibrinolysis to } \\
\text { coronary intervention, median } \\
\text { (days) (IQR: 25th, 75th } \\
\text { percentile) }\end{array}$ & 5.5 (IQR:2.9,9.1) & 6.2 (IQR: $3.1,10.3$ ) & 0.625 \\
\hline LVEF (\%) & $54.5 \pm 11.1$ & $53.1 \pm 12.9$ & 0.306 \\
\hline GRACE score, mean $\pm S D$ & $100.1 \pm 17.7$ & $142.2 \pm 14.3$ & $<0.001$ \\
\hline \multicolumn{4}{|l|}{ Medical conditions, n (\%) } \\
\hline Smoking & $145(63.8)$ & $62(55.4)$ & 0.151 \\
\hline Hypertension & $103(45.0)$ & $57(50.9)$ & 0.355 \\
\hline Diabetes & $48(20.9)$ & 17 (15.2) & 0.241 \\
\hline Dyslipidaemia & $104(45.8)$ & $32(28.6)$ & 0.002 \\
\hline Smoking & $145(63.8)$ & $62(55.4)$ & 0.155 \\
\hline Chronic kidney disease & $11(4.8)$ & $10(9.0)$ & 0.151 \\
\hline Prior PCl & $2(0.9)$ & $6(5.4)$ & 0.017 \\
\hline \multicolumn{4}{|l|}{ Medications, n (\%) } \\
\hline Aspirin & $229(100)$ & $112(100)$ & NA \\
\hline Clopidogrel & $220(96.1)$ & $107(95.5)$ & 0.779 \\
\hline $\begin{array}{l}\text { Low molecular weight } \\
\text { heparin }\end{array}$ & $209(91.7)$ & $103(92.0)$ & 0.554 \\
\hline ACEI/ARB & 167 (72.9) & $88(78.6)$ & 0.260 \\
\hline Beta-blocker & $144(62.8)$ & $72(64.2)$ & 0.801 \\
\hline
\end{tabular}

Data presented as $\mathrm{n}(\%)$ or mean $\pm \mathrm{SD}$ or median (IQR).

ACEI/ARB, angiotensin-converting enzyme inhibitors/angiotensin receptor blockers; GRACE, Global Registry for Acute Coronary

Events; LVEF, left ventricular ejection fraction; NA, not applicable; $\mathrm{PCl}$, percutaneous coronary intervention.

patients were completely followed up at 6 months in both groups. The baseline clinical characteristics are shown in table 1 . The median time from fibrinolytic therapy to coronary intervention in low GRACE risk score group was 5.5 days (IQR, 2.9 to 9.1) and 6.2 days (IQR,3.1 to 10.3 ) in intermediate-high GRACE risk score group ( $p$ value $=0.625)$.

\section{Angiographic and procedural details}

Angiographic and procedural details are presented in table 2. No different in infarct-related artery in both groups. Double vessel disease and triple vessel disease were presented in $48.5 \%$ and $66.1 \%$ in low GRACE risk score group and intermediate-high GRACE risk score group, respectively. Sixty-six percent $(n=152)$ of the patients in low GRACE risk score group and $63.4 \%$ $(n=71)$ of the patients in intermediate-high GRACE risk 


\begin{tabular}{|c|c|c|c|}
\hline $\begin{array}{l}\text { Angiographic data and } \\
\text { procedural details }\end{array}$ & $\begin{array}{l}\text { Low GRACE } \\
\text { score group } \\
(n=229)\end{array}$ & $\begin{array}{l}\text { Intermediate- } \\
\text { high GRACE } \\
\text { score group } \\
(n=112)\end{array}$ & $P$ value \\
\hline Infarct-related artery, n (\%) & & & 0.414 \\
\hline Non-anterior & $129(56.3)$ & $69(61.6)$ & \\
\hline Anterior & $100(43.7)$ & $43(38.4)$ & \\
\hline \multicolumn{4}{|l|}{ Angiographic findings, $\mathrm{n}(\%)$} \\
\hline Normal or mild disease & $13(5.7)$ & $4(3.5)$ & 0.597 \\
\hline Single vessel disease & $105(45.8)$ & $34(30.4)$ & 0.007 \\
\hline Double vessel disease & $59(25.8)$ & $33(29.5)$ & 0.516 \\
\hline Triple vessel disease & $52(22.7)$ & $41(36.6)$ & 0.009 \\
\hline \multicolumn{4}{|l|}{ Procedural performed } \\
\hline CAG without $\mathrm{PCl}, \mathrm{n}(\%)$ & $77(33.6)$ & $41(36.6)$ & 0.628 \\
\hline Medical treatment & $61(79.2)$ & $24(58.5)$ & 0.03 \\
\hline CABG & $16(20.8)$ & $17(41.5)$ & 0.03 \\
\hline $\mathrm{PCl}, \mathrm{n}(\%)$ & $152(66.4)$ & $71(63.4)$ & 0.628 \\
\hline Culprit vessel PCl & $137(90.1)$ & $65(91.5)$ & 0.811 \\
\hline Multi-vessel PCI & $15(9.9)$ & $6(8.5)$ & 0.811 \\
\hline \multicolumn{4}{|l|}{ Procedural details, $n(\%)$} \\
\hline POBA & $8(5.2)$ & $10(14.0)$ & 0.033 \\
\hline Thrombus aspiration & $0(0)$ & $3(4.2)$ & 0.031 \\
\hline Bare metal stent & 45 (29.6) & $12(17.1)$ & 0.068 \\
\hline Drug eluting stent & $101(66.9)$ & $52(74.3)$ & 0.347 \\
\hline
\end{tabular}

Data presented as $\mathrm{n}(\%)$.

CABG, coronary artery bypass graft; CAG, coronary angiography; GRACE, Global Registry for Acute Coronary Events; PCl, percutaneous coronary intervention; POBA, plain old balloon angioplasty.

score group underwent PCI ( $\mathrm{p}$ value $=0.628$ ), while $33.6 \%$ of the patients in the low GRACE risk score group $(\mathrm{n}=71)$ and $36.6 \%(\mathrm{n}=41)$ of the patients in the intermediatehigh GRACE risk score group performed only CAG ( $p$ value $=0.628$. Culprit vessel PCI was performed in $90.1 \%$ $(\mathrm{n}=137)$ of the patients in the low GRACE score group and $91.5 \%(\mathrm{n}=65)$ of the patients in the intermediatehigh GRACE risk score group ( $\mathrm{p}$-value $=0.811$ ). Among the patients who underwent PCI, 66.9\% (n=101) of the patients in the low GRACE risk score group and $72.4 \%(\mathrm{n}=52)$ of the patients in the intermediate-high GRACE risk score group received drug-eluting stent ( $p$ value $=0.347$ ).

\section{0-day and 6-month cardiovascular outcomes}

At 30 days, the composite cardiovascular outcome occurred in five patients $(2.2 \%)$ in the low GRACE risk score group and 13 patients $(11.6 \%)$ in the intermediate-high GRACE risk score group ( $p$ value $=0.001$ ). At 6 months, the composite cardiovascular outcome occurred in nine patients (3.9\%) in low GRACE risk score group and 15 patients $(13.4 \%)$ in the intermediate-high GRACE risk group ( $p$ value $=0.003$ ) (table 3 ). The in-hospital mortality
Table 3 Clinical cardiovascular outcomes at 30 days and 6 months of follow-up ( $n=341)$

\begin{tabular}{|c|c|c|c|}
\hline Clinical outcomes & $\begin{array}{l}\text { Low GRACE } \\
\text { score group } \\
(\mathrm{n}=229)\end{array}$ & $\begin{array}{l}\text { Intermediate- } \\
\text { high GRACE } \\
\text { score group } \\
(\mathrm{n}=112)\end{array}$ & $P$ value \\
\hline In-hospital mortality, n (\%) & $1(0.4)$ & $2(1.8)$ & 0.252 \\
\hline In-hospital stroke, n (\%) & $0(0)$ & $0(0)$ & NA \\
\hline \multicolumn{4}{|l|}{ At 30 days } \\
\hline Composite CV outcomes & $5(2.2)$ & $13(11.6)$ & 0.001 \\
\hline Re-hospitalised with ACS & $3(1.3)$ & $1(0.9)$ & 0.601 \\
\hline Re-hospitalised with HF & $1(0.4)$ & $9(8.0)$ & $<0.001$ \\
\hline Stroke & $0(0)$ & $1(0.9)$ & 0.328 \\
\hline CV death & $1(0.4)$ & $2(1.8)$ & 0.252 \\
\hline Non-CV death & $0(0)$ & $0(0)$ & NA \\
\hline Loss to follow-up & $0(0)$ & $0(0)$ & NA \\
\hline \multicolumn{4}{|l|}{ At 6 months (cumulative) } \\
\hline Composite CV outcomes* ${ }^{*}$ & $9(3.9)$ & $15(13.4)$ & 0.003 \\
\hline Re-hospitalised with ACS & $6(2.6)$ & $1(0.9)$ & 0.433 \\
\hline Re-hospitalised with HF & $2(0.8)$ & $10(8.9)$ & $<0.001$ \\
\hline Stroke & $0(0)$ & $2(1.8)$ & 0.107 \\
\hline CV death & $1(0.4)$ & $2(1.8)$ & 0.252 \\
\hline Non-CV death & $0(0)$ & $0(0)$ & NA \\
\hline Loss to follow-up & $0(0)$ & $0(0)$ & NA \\
\hline
\end{tabular}

Data presented as $\mathrm{n}(\%)$.

${ }^{*}$ Crude hazard ratio for 6 -month composite CV outcome was 5.02 $(95 \% \mathrm{Cl} 2.47$ to $10.20, \mathrm{p}<0.001)$.

†Adjusted HR for 6-month composite CV outcome (adjusted by dyslipidaemia, angiographic findings and $\mathrm{PCl}$ performed) was 4.79 $(95 \% \mathrm{Cl} 2.28$ to $10.04, \mathrm{p}<0.001)$.

ACS, acute coronary syndrome; CV, cardiovascular; GRACE, Global Registry for Acute Coronary Events; HF, heart failure; NA, not applicable.

occurred in one patient $(0.4 \%)$ and two patients $(1.8 \%)$ in the low and intermediate-high GRACE risk score groups, respectively ( $p$ value $=0.252$ ). Rate of re-hospitalised with $\mathrm{HF}$ at 1 and 6 months was higher in the intermediate-high GRACE risk score group compared with the low GRACE group $(8.0 \%$ vs $0.4 \%$, p value $<0.001 \%$ and $8.9 \%$ vs $0.8 \%$, $\mathrm{p}$ value $<0.001$, respectively). The composite cardiovascular outcome at 6 months was higher in the intermediate-high GRACE group compared with the low GRACE group (OR: $5.69,95 \%$ CI: 2.69 to $12.07 ; \mathrm{p}<0.001)$.

\section{GRACE score and cardiovascular outcomes}

The cumulative of a composite cardiovascular outcome was higher in the intermediate-high GRACE risk score group compared with the low GRACE risk score group (crude hazard ratio $5.02,95 \% \mathrm{CI} 2.47$ to $10.20, \mathrm{p}<0.001$ ), as shown in figure 3. After adjusted by dyslipidaemia, angiographic findings and PCI performed, adjusted HR of GRACE risk score group for 6-month composite cardiovascular outcome was 4.79 (95\% CI 2.28 to $10.04, \mathrm{p}<0.001)$. The usefulness of GRACE score for a 6-month composite cardiovascular outcome was represented with the AuROC. The AuROC was 0.746 (95\% CI 0.69 to 0.79 ), as shown in figure 4 . 


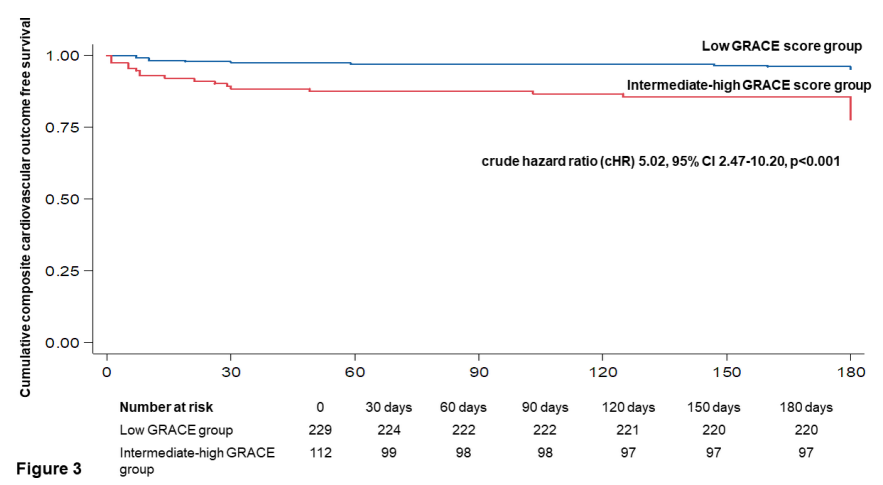

Figure 3 Kaplan-Meier curve for 6-month cumulative composite cardiovascular outcomes according to GRACE groups.

\section{DISCUSSION}

Several randomised trials and meta-analysis have shown that early routine post-thrombolytic angiography and PCI reduced the rates of re-infarction and recurrent ischaemia compared with ischemia-guided strategy. ${ }^{89}$ Although early coronary intervention (3-24hours) after fibrinolytic treatment is recommended by several practice guidelines, ${ }^{1-5}$ timely CAG or PCI is not widely available in countries with limited PCI-capable hospitals, especially in the Northern Thailand. Many studies such as SIAM-III (Southwest German Interventional Study in Acute Myocardial infarction study group),${ }^{10}$ TRANSFER-AMI (the Trial of Routine ANgioplasty and Stenting after Fibrinolysis to Enhance Reperfusion in Acute Myocardial Infarction), ${ }^{11}$ NORDISTEMI (the NORwegian study on DIstrict treatment of ST elevation myocardial infarction), ${ }^{12}$ and CARESS-AMI (the combined Abciximab REteplase Stent Study in Acute Myocardial Infarction) ${ }^{13}$ revealed the worse cardiovascular outcomes in STEMI patients who underwent the delayed coronary intervention after thrombolytic therapy.

The GRACE risk score has shown to be a good risk stratification score in population with STEMI and NSTE-ACS (non ST-segment elevation acute coronary syndromes or acute coronary syndromes without ST-segment elevation). ${ }^{14-18}$ The validation and the usefulness of GRACE score in

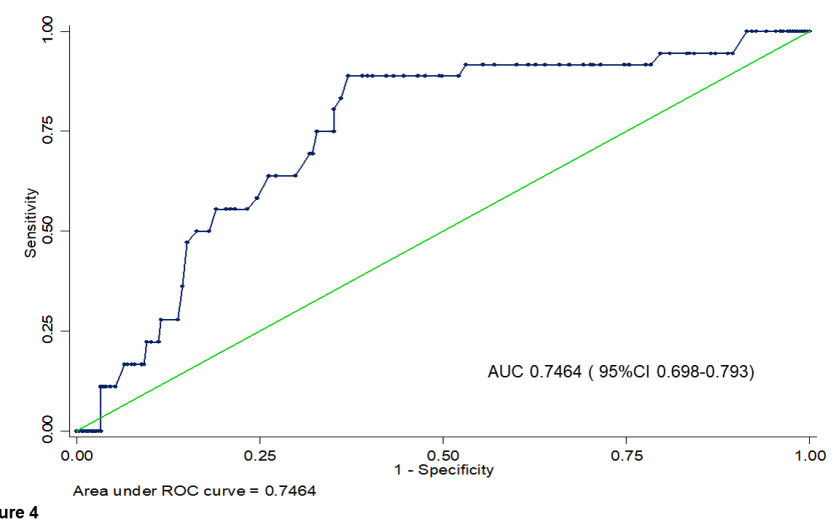

Figure 4 The area under the receiver operating characteristics curve (AuROC) for the performance of GRACE score in predicting 6-month composite cardiovascular outcomes. stratified STEMI patients for an early invasive management was shown in several studies, AuROC was 0.81 (95\% CI 0.800.82). ${ }^{19}{ }^{20}$ Previous data in non-PCI capable hospital, risk stratification was necessary for the clinicians and cardiologists to guide judgement and selection of an early invasive strategy. ${ }^{7}$ However, it is unclear in limited PCI-capable hospitals.From this study, the GRACE risk score seemed to have a better performance (AUC=0.746, 95\% CI 0.70-0.79) in predicting 6-month composite cardiovascular outcomes in a setting of limited PCI-capable center and underwent the delayed coronary intervention than non-PCI capable hospital (AUC=0.641, 95\% CI 0.52-0.76). ${ }^{7} \mathrm{~A}$ GRACE risk score explained a $74.6 \%$ probability in predicting 6 -month composite cardiovascular outcome based on the receiver operating characteristic (ROC) analysis. Therefore, in the limited PCIcapable hospitals, the GRACE risk score may be helpful to classify the STEMI patients for the early vs delayed coronary intervention after fibrinolytic therapy.

The data from subgroup analysis of TRANSFER-AMI showed better outcomes of early coronary intervention only in patient with a low-intermediate GRACE risk score $(<155)$, while the early invasive strategy was associated with worst outcome in high-risk patients $(\geq 155) .{ }^{21}$ In our study, the stratified GRACE risk score group was different from the subgroup analysis of TRANSFER-AMI. From this study, GRACE risk score may help cardiologists in finding the best strategy to achieve and maintain myocardial reperfusion after administration of fibrinolytic therapy. ${ }^{21}$ Similar to our study, the delayed coronary intervention in limited PCI-capable facilities may be associated with the worst clinical outcomes at 30 days and 6 months when compared with the patients with low GRACE risk score $(11.6 \%$ vs $2.2 \%$ at 30 days, $p$ value $=0.001 \%$ and $13.4 \%$ vs $3.9 \%$ at 6 months, $p$ value $=0.003$ ). Therefore, the patients with the intermediatehigh GRACE risk score in PCI-capable hospital should perform an early coronary intervention after fibrinolytic therapy, especially on index admission and can be a guide for the limited PCI-capable hospital situation.

The in-hospital mortality and 6-month mortality of our study were lower than those of the previous registry (TRACS) because of differences in patient demographics data, the presentation and number of patients receiving PCI during admission index (in-hospital mortality $5.3 \%$ vs $0.9 \%$ and 6 -month mortality $12.1 \%$ vs $0.9 \%) .{ }^{67}$

There are some limitations in our study. Our study was a retrospective cohort study. A large number of patients were excluded due to limitation of coronary intervention within 2 weeks after fibrinolytic therapy. The mortality was lower than that in the earlier study because of small number of patients with high GRACE risk included in our study.

\section{CONCLUSION}

Our study showed the light of the usefulness of the GRACE risk score to guide cardiologists in limited PCIcapable hospitals to an early coronary intervention in postfibrinolytic STEMI patients as similar as in non-PCI-capable hospitals. The intermediate-high GRACE risk score in 
STEMI patients who underwent the delayed coronary intervention after fibrinolytic therapy in PCI-capable hospitals increased the rate of short/long-term cardiovascular outcomes compared with low GRACE risk patients.

\section{Author affiliations}

${ }^{1}$ Department of Internal Medicine, Lampang Hospital, Lampang, Thailand

${ }^{2}$ Clinical Epidemiology Program, Clinical Epidemiology and Clinical Statistics Center, Department of Clinical Epidemiology, Faculty of Medicine, Chiang Mai University, Chiang Mai, Thailand

${ }^{3}$ Department of Internal Medicine, Faculty of Medicine, Chiang Mai University, Chiang Mai, Thailand

${ }^{4}$ Department of Pharmacy, Lampang Hospital, Lampang, Thailand

${ }^{5}$ Department of Pharmaceutical Care, Faculty of Pharmacy, Chiangmai University, Chiang Mai, Thailand

${ }^{6}$ Pharmacoepidemiology and Statistics Research Center (PESRC), Faculty of

Pharmacy, Chiangmai University, Chiang Mai, Thailand

${ }^{7}$ Center of Excellence in Applied Epidemiology, Faculty of Medicine, Thammasat University, Pathumthani, Thailand

${ }^{8}$ Department of Clinical Epidemiology, Faculty of Medicine, Chiang Mai University, Chiang Mai, Thailand

${ }^{9}$ Cardiac Catheterization Laboratory Unit, Department of Internal Medicine, Faculty of Medicine, Chiang Mai University, Chiang Mai, Thailand

Acknowledgements Thank you all staff of Chiang Mai University and Lampang Hospital. Many thanks to all nurses and administers in the Northern Cardiac Center of Chiang Mai University and Lampang hospital.

Contributors All authors made substantial contributions to conception, design and drafting the manuscript. YC designed the study, conducted the data collection, analysis and prepared the manuscript. AP, SK, RM, CR, JP, TC, NT, TB and AS conducted a critical review of the manuscript and provided final editing to the manuscript. All authors read and approved the final manuscript.

Funding Funding used to conduct this study and prepare this manuscript was supported by Faculty of Medicine, Chiang Mai University.

Competing interests None declared.

Patient consent for publication Not required.

Ethics approval The protocol was reviewed and approved by the Research Ethics Committee 4, Faculty of Medicine, Chiang Mai University and Research Ethics Committee of Lampang Hospital. Informed consent was confirmed by the Research Ethic Committee 4, Faculty of Medicine, Chiang Mai University. The patient's inform consent was waived due to the nature of retrospective study.

Provenance and peer review Not commissioned; externally peer reviewed.

Data availability statement Data are available upon reasonable request.

Open access This is an open access article distributed in accordance with the Creative Commons Attribution Non Commercial (CC BY-NC 4.0) license, which permits others to distribute, remix, adapt, build upon this work non-commercially, and license their derivative works on different terms, provided the original work is properly cited, appropriate credit is given, any changes made indicated, and the use is non-commercial. See: http://creativecommons.org/licenses/by-nc/4.0/.

ORCID iD

Yotsawee Chotechuang http://orcid.org/0000-0003-2531-2900

\section{REFERENCES}

1 Wijns W, Kolh P, Danchin N, et al. Guidelines on myocardial revascularization. The task force on myocardial revascularization of the European Society of cardiology (ESC) and the European association for Cardio-Thoracic surgery (EACTS). developed with the special contribution of the European association for percutaneous cardiovascular interventions (EAPCI). Eur Heart J 2010;31:2501-55.

2 Steg PG, James SK, Atar D, et al. Esc guidelines for the management of acute myocardial infarction in patients presenting with ST-segment elevation. Eur Heart J 2012;33:2569-619.

3 Levine GN, Bates ER, Blankenship JC, et al. 2011 ACCF/AHA/ SCAl guideline for percutaneous coronary intervention. A report of the American College of cardiology Foundation/American heart association Task force on practice guidelines and the Society for cardiovascular angiography and interventions. J Am Coll Cardiol 2011;58:e44-122.

4 O'Gara PT, Kushner FG, Ascheim DD, et al. 2013 ACCF/AHA guideline for the management of ST-elevation myocardial infarction: a report of the American College of cardiology Foundation/American heart association Task force on practice guidelines. Circulation 2013;127:e362-425.

5 Windecker S, Kolh P, Alfonso F, et al. 2014 ESC/EACTS Guidelines on myocardial revascularization: The Task Force on Myocardial Revascularization of the European Society of Cardiology (ESC) and the European Association for Cardio-Thoracic Surgery (EACTS) Developed with the special contribution of the European Association of Percutaneous Cardiovascular Interventions (EAPCI). Eur Heart $J$ 2014;35:2541-619.

6 Srimahachota S, Boonyaratavej S, Kanjanavanit R, et al. Thai Registry in Acute Coronary Syndrome (TRACS)--an extension of Thai Acute Coronary Syndrome registry (TACS) group: lower in-hospital but still high mortality at one-year. J Med Assoc Thai 2012;95:508-18.

7 Chotechuang Y, Phrommintikul A, Muenpa R, et al. The prognostic utility of GRACE risk score in predictive cardiovascular event rate in STEMI patients with successful fibrinolysis and delay intervention in non PCl-capable Hospital: a retrospective cohort study. BMC Cardiovasc Disord 2016;16:212.

8 Borgia F, Goodman SG, Halvorsen S, et al. Early routine percutaneous coronary intervention after fibrinolysis vs. standard therapy in ST-segment elevation myocardial infarction: a metaanalysis. Eur Heart J 2010;31:2156-69.

9 D'Souza SP, Mamas MA, Fraser DG, et al. Routine early coronary angioplasty versus ischaemia-guided angioplasty after thrombolysis in acute ST-elevation myocardial infarction: a meta-analysis. Eur Heart J 2011;32:972-82.

10 Scheller B, Hennen B, Hammer B, et al. Beneficial effects of immediate stenting after thrombolysis in acute myocardial infarction. J Am Coll Cardiol 2003;42:634-41.

11 Cantor WJ, Fitchett D, Borgundvaag B, et al. Routine early angioplasty after fibrinolysis for acute myocardial infarction. $N$ Engl $J$ Med 2009;360:2705-18.

12 Bøhmer E, Hoffmann P, Abdelnoor M, et al. Efficacy and safety of immediate angioplasty versus ischemia-guided management after thrombolysis in acute myocardial infarction in areas with very long transfer distances results of the NORDISTEMI (Norwegian study on district treatment of ST-elevation myocardial infarction). J Am Coll Cardiol 2010;55:102-10.

13 Di Mario C, Dudek D, Piscione F, et al. Immediate angioplasty versus standard therapy with rescue angioplasty after thrombolysis in the combined abciximab reteplase stent study in acute myocardial infarction (CARESS-in-AMI): an open, prospective, randomised, multicentre trial. Lancet 2008;371:559-68.

14 GRACE Investigators. Rationale and design of the grace (global registry of acute coronary events) project: a multinational registry of patients hospitalized with acute coronary syndromes. Am Heart $J$ 2001;141:190-9.

15 Eagle KA, Lim MJ, Dabbous $\mathrm{OH}$, et al. A validated prediction model for all forms of acute coronary syndromes in an international registry. JAMA 2004;291:2727-33.

16 Granger CB, Goldberg RJ, Dabbous O, et al. Predictors of hospital mortality in the global registry of acute coronary events. Arch Intern Med 2003;163:2345-53.

17 Fox KAA, Carruthers KF, Dunbar DR, et al. Underestimated and under-recognized: the late consequences of acute coronary syndrome (grace UK-Belgian study). Eur Heart J 2010;31:2755-64.

18 Tang EW, Wong C-K, Herbison P. Global registry of acute coronary events (grace) hospital discharge risk score accurately predicts long-term mortality post acute coronary syndrome. Am Heart $J$ 2007;153:29-35.

19 D'Ascenzo F, Biondi-Zoccai G, Moretti C, et al. Timi, grace and alternative risk scores in acute coronary syndromes: a meta-analysis of 40 derivation studies on 216,552 patients and of 42 validation studies on 31,625 patients. Contemp Clin Trials 2012;33:507-14.

20 Elbarouni B, Goodman SG, Yan RT, et al. Validation of the global registry of acute coronary event (grace) risk score for in-hospital mortality in patients with acute coronary syndrome in Canada. Canadian global registry of acute coronary events (GRACE/ grace (2)) Investigators. Am Heart J 2009;158:392-9.

21 Yan AT, Yan RT, Cantor WJ, et al. Relationship between risk stratification at admission and treatment effects of early invasive management following fibrinolysis: insights from the trial of routine angioplasty and stenting after fibrinolysis to enhance reperfusion in acute myocardial infarction (TRANSFER-AMI). Eur Heart $J$ 2011;32:1994-2002. 